\title{
ASO Author Reflections: D2 Lymphadenectomy Must be Complied No Matter the Arterial Variation
}

\author{
Andre Roncon Dias, MD, PhD (1) \\ Cancer Institute, Hospital Das Clinicas, University of Sao Paulo Medical School, Sao Paulo, Brazil
}

\section{PAST}

Gastrectomy with D2 lymphadenectomy is the main treatment for advanced gastric cancer. It is technically demanding and implies clearing the lymph nodes along the celiac trunk and its branches. Surgeon compliance with D2, especially in the west, has frequently been questioned. In the Dutch trial (D1 vs. D2), $81.5 \%$ of the D2 patients had inadequate lymph node removal. ${ }^{1}$ Additionally, D2 has considerable morbidity and eastern outcomes are hard to match. ${ }^{2}$

Vascular variations of the gastric and hepatic irrigation are observed in $25 \%$ of patients. They increase the risk for unattended vessel injuries, bleeding, inadequate lymph node resection, and extend surgical duration. ${ }^{3}$

\section{PRESENT}

Solid data supporting laparoscopic gastrectomy for advanced gastric cancer has been recently published and it is now gaining worldwide acceptance. ${ }^{4}$ Because open D2 is still a concern, worst results may be anticipated with the minimally invasive access (robotic included). In this context, arterial variations (besides all previously mentioned risks) raise the technical challenge and the chance for conversion. The present video was created to mitigate this. ${ }^{5}$ It shows how to identify preoperatively the arterial variation and provides strategies to perform D2 lymphadenectomy safely in different anatomic settings. This knowledge is fundamental to surgeons who manage gastric cancer; however, practical data are currently lacking.

(C) Society of Surgical Oncology 2020

First Received: 3 November 2020

Accepted: 3 November 2020;

Published Online: 20 November 2020

A. R. Dias, MD, $\mathrm{PhD}$

e-mail: roncon86@hotmail.com

\section{FUTURE}

For those with anatomical variation, peritumoral injection of indocyanine green is an interesting strategy and should be studied. It has the ability to reveal the lesion's lymphatic drainage.

Finally, further studies are required to determine the therapeutic value of removing those lymph nodes around the hepatic branch that comes from the superior mesenteric artery, and those located over the portal vein in the absence of the common hepatic artery. Until then, we must comply with D2 and remove stations as indicated in the video.

DISCLOSURE The author declare that the present submission had no funding and there is no conflict of interest.

\section{REFERENCES}

1. Bonenkamp JJ, Hermans J, Sasako M, van De Velde CJ. Quality control of lymph node dissection in the Dutch randomized trial of D1 and D2 lymph node dissection for gastric cancer. Gastric Cancer. 1998;1(2):152-9.

2. Bickenbach K, Strong VE. Comparisons of gastric cancer treatments: east vs. west [published correction appears in J Gastric Cancer. 2012;12(4):262]. J Gastric Cancer. 2012;12(2):55-62.

3. Huang Y, Mu GC, Qin XG, Chen ZB, Lin JL, Zeng YJ. Study of celiac artery variations and related surgical techniques in gastric cancer. World J Gastroenterol. 2015;21(22):6944-51.

4. Lee HJ, Hyung WJ, Yang HK, Han SU, Park YK, An JY, et al. Short-term outcomes of a multicenter randomized controlled trial comparing laparoscopic distal gastrectomy with D2 lymphadenectomy to open distal gastrectomy for locally advanced gastric cancer (KLASS-02-RCT). Ann Surg. 2019;270(6):983-91.

5. Dias AR, Charruf AZ, Ramos MFKP, Ribeiro Jr U, Zilberstein B, Cecconello I. D2 lymphadenectomy according to the arterial variations in gastric and hepatic irrigation. Ann Surg Oncol. 2020. https://doi.org/10.1245/s10434-020-09316-6.

Publisher's Note Springer Nature remains neutral with regard to jurisdictional claims in published maps and institutional affiliations. 